\title{
Predictors of Physical Activity in Retired Women on the Basis of the Planned Behavior Theory
}

\section{Golbahar Farsi Astaneh ${ }^{1}$, Abdolhosein Emami Sigaroudi ${ }^{2, *}$, Rabiollah Farmanbar ${ }^{3}$, Zahra Atrkar} Roushan $^{4}$

1- Master Student in Community Heath Nursing, Department of Nursing, School of Nursing and Midwifery, Guilan University of Medical Sciences, Rasht, Iran. ORCID ID: 0000-0003-3069-3648

2-Associate Professor of Nursing Education, Cardiovascular Diseases Research Center, Department of Cardiology, Heshmat Hospital, School of Medicine, Guilan University of Medical Sciences, Rasht, Iran., Email: icrc.inf2019@ gmail.com, ORCID ID: 0000-0002-1394-3361

3-Associate Professor of Health Education and Promotion, Social Determinants of Health Research Center, Guilan University of Medical Sciences, Rasht, Iran. ORCID ID: 0000-0002-7220-688X

4- Associate Professor of Biostatistics, Bio-Statistics, School of Medicine, Guilan University of Medical Science, Rasht, Iran. ORCID ID: 0000-0002-1267-2133

\begin{abstract}
Background and Aim: Physical activity, especially in women, decreases with age, which can lead to disabling fractures in the elderly. In this study, we investigated the factors related to physical activity based on the theory of planned behavior in retired women in Rasht City from 2017 to 2018.

Materials and Methods: This analytical cross-sectional study was included 196 female members of ten active retirement centers in Rasht City in 2017. We designed a questionnaire on the basis of Ajzen's planned behavioral model which included regular physical activity, perceived behavioral control, behavioral intention, attitude, and subjective norms. A standardized physical activity questionnaire was used for the elderly. The method of data collection was an interview. Using SPSS software version 16, data were analyzed by a descriptive statistical method and pearson correlation coefficient. $\mathrm{p}<0.05$ was considered significant.

Results: The results showed that the mean value for the physical activity of the elderly was $329.18 \pm 28.18$, which was about $\% 82$ of the PASE tool score. Planned behavior theory constructs and underlying demographic variables had no significant effect on PASE. We found a significant relationship between behavioral intention and perceived behavioral control, and also between attitude and perceived behavioral control. Attitude had significant correlations with behavioral intention and subjective norms.
\end{abstract}

Conclusions: Although the relationship between planned behavior model constructs and physical activity were not significant in this study, planned behavior theory constructs had significant relationships with one another.

Keywords: Physical activity, Women, Retirement ,Planned behavior theory

Received: Oct 5, 2019

Accepted: May 16, 2020

How to cite the article: Golbahar Farsi Astaneh, Abdolhosein Emami Sigaroudi,Rabiollah Farmanbar, Zahra Atrkar Roushan. Predictors of physical activity in retired women on the basis of the planned behavior theory. SJKU. 2021;25(6):115-126.

Copyright () 2018 the Author (s). Published by Kurdistan University of Medical Sciences. This is an open access article distributed under the terms of the Creative Commons Attribution-Non-Commercial License 4.0 (CCBYNC), where it is permissible to download, share, remix, transform, and buildup the work provided it is properly cited. The work cannot be used commercially without permission from the journal 


\section{ييش بينى كننله هاى فعاليت فيزيكى بانوان بازنشسته بر اساس تئورى رفتار برنامه ريزىشلهه}

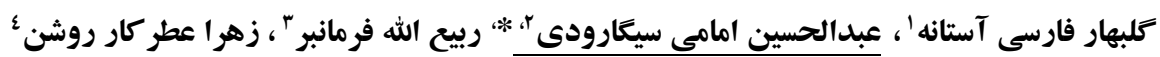

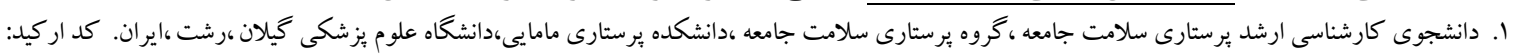
.0000-0003-3069-3648

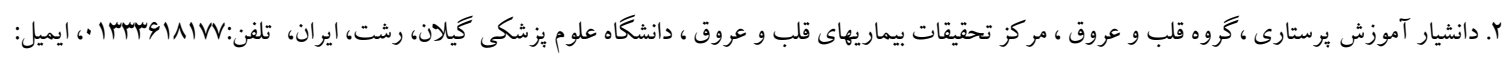
0000-0002-1394-3361: icrc.inf2019@gmail.com r. دانشيار آموزش بهداشت و ارتقا سلامت ،گروه بهداشت و ارتقائ سلامت، دانشكده بهداشت ،دانشكاه علوم يز شكى گيلان، رشت، ايران. كد اركيد: -0002-0002-000 7220-688X/

F. استاديار آمار زيستى، كروه آمار، مر كز تحقيقات عوامل اجتماعى سلامت، دانشخاه علوم يزشكى گيلان،رشت،ايران. كد اركيد:2133-0000-0002-1267

\section{جكيuه}

زمينه و هدف: با افزايش سن فعاليت فيزيكى بخصوص در زنان كاهش مى يابد كه منجر به بروز شكستكىهاى ناتوان كننده در

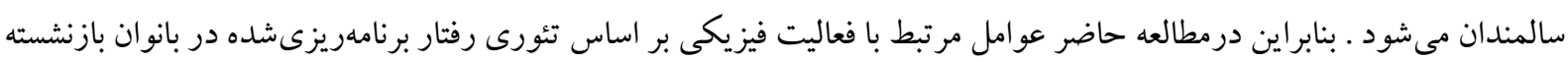

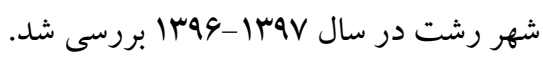

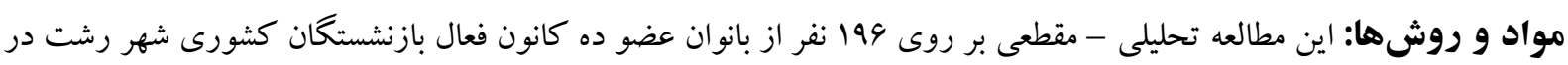

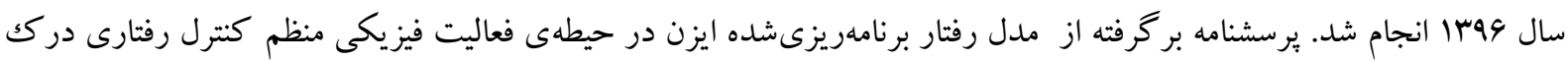

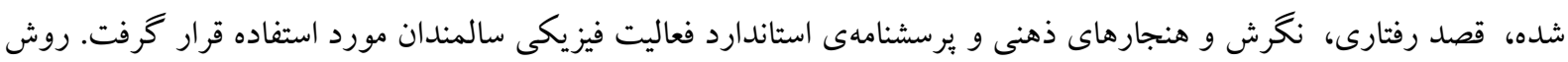

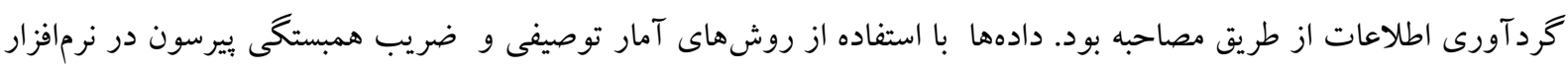
نسخه 19 مورد تجزيهو تحليل قرار گرفت ــ هـ/PSS

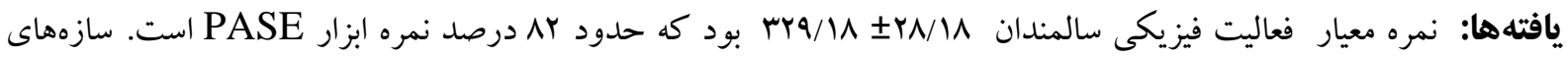

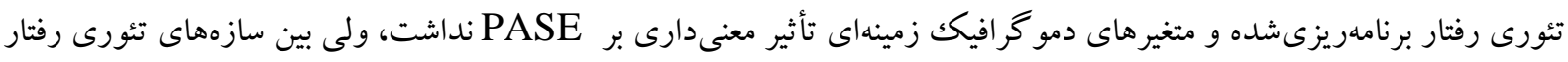

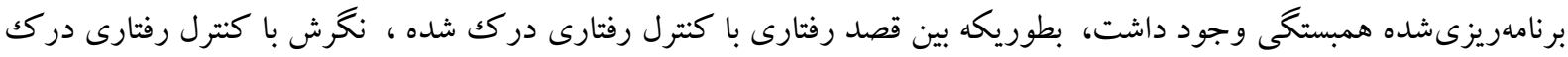

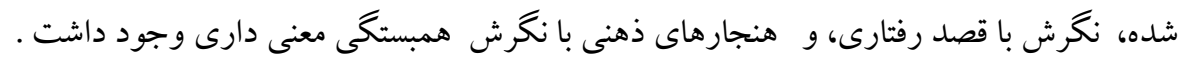

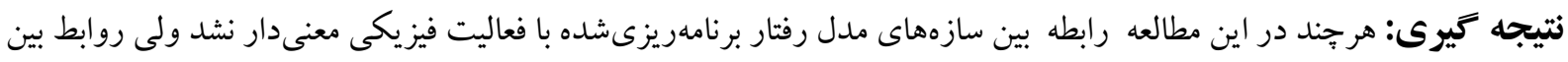

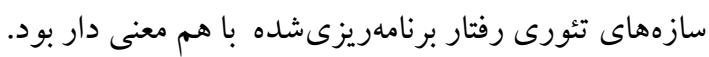

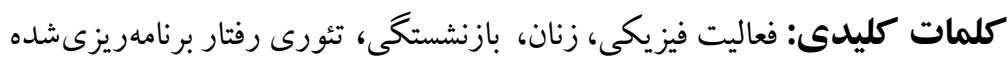
وصول مقاله:QN/V/YT اصلاحيه نهايى:9 
امروزه تلاش براى اندازهگيرى تعيين كنندهاى روانى

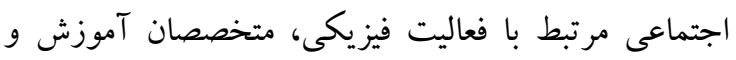

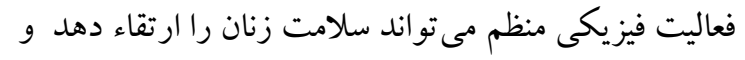

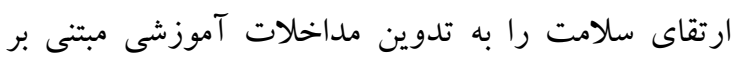

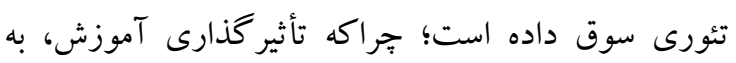
استفاده مناسب از تئورىهاى علوم رفتارى بستگى دارد (Y I ا). تئورى هاى علوم رفتارى و اجتماعى بسترى فراهم مى كنند تا نأن

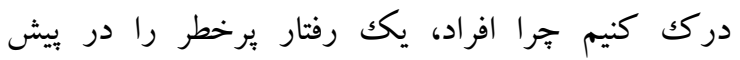
مى گيرند يا اينكه تجرا يكك رفتار حفاظتى را انجام مى دهند.

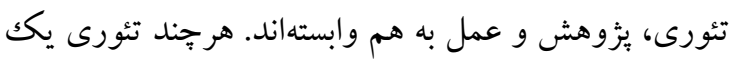

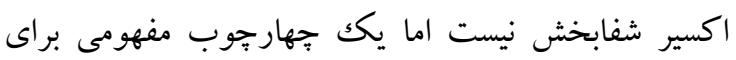

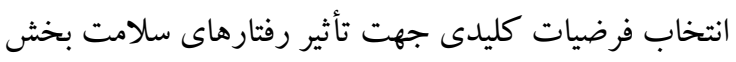

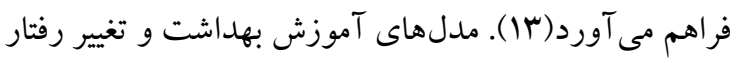

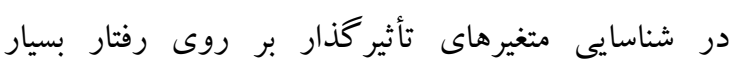

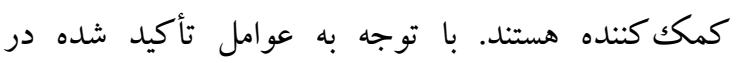
مطالعات صورت گرفته به نظر مىرسد تئورى رفتار

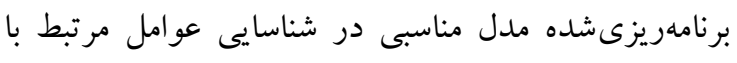

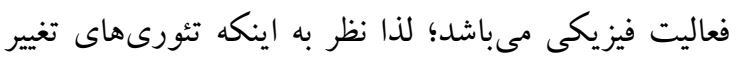

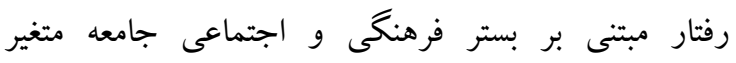

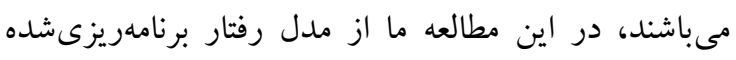

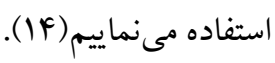
تئورى رفتـار برنامهريزى شـــه شـكل تكامل يافتسى تئسورى عمـل منطقىى) (Theory Of Reasoned Action) است(10, 19)در اين تئورى عنصر جديدى با عنوان كنترل

رفتارى درك شده Perceived Behavioral) Control ( اضافهده است كه تعيين كنندهى تمايلات رفتارى و رفتـار اسـتفاده مىباشـــ(IV)|يـن تئسورى شـامل ســازهاى قصـــ رفتـارى(Intention) ) ، نخـرش (Attitude) ، ،هنجارهـاى ذهنى (Subjective Norms) و كنتـرل رفتـارى درك شده مىباشد؛ كه توسط آيزن و فيش بن مطرح شد و بهطور گسترده در مطالعات مختلف جهت تعيين نخرش و باورهاى

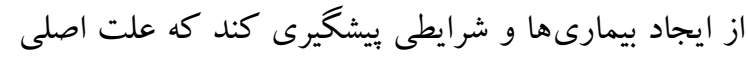
مرك و ناتوانى زنان در سراسر جهان هستند. همجنين سلامت روانى زنان را با كاهش سطوح استرس، اضطراب،

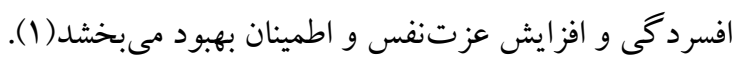

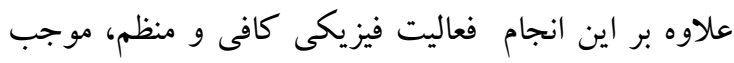
كاهش فشارخون بالا، بيمارى قلبى -عروقى، سكته مغزى،

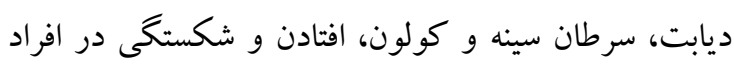
بزرگكسال مى شود. فعاليت فيزيكى، سلامت و وملكرد

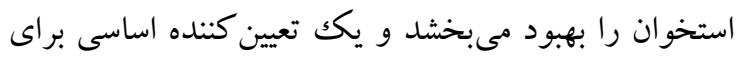

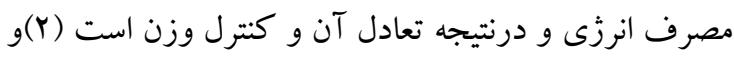

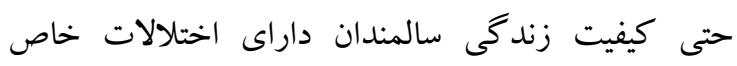

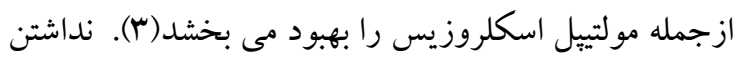

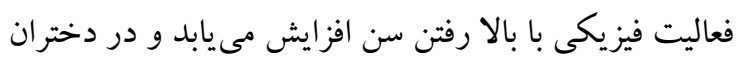
و زنان، بالاتر از يسران و مردان است (F). بسيارى از تغييرات

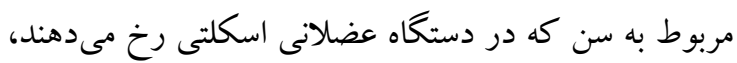

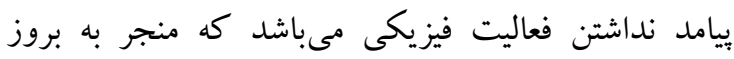

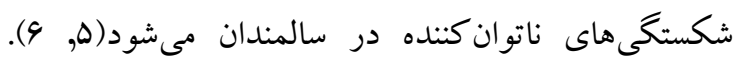
علاوه بر اين گزارش شده است زنانى كه فعاليت كمترى

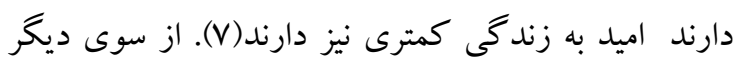
تصميمات زنان روى فعاليت فيزيكى خانو اده مؤثر است(A).

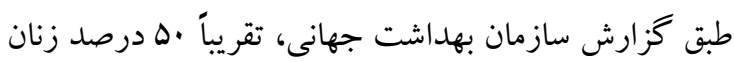

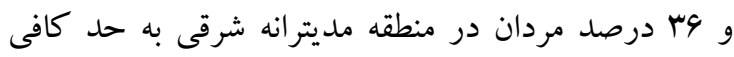
فعال نيستد(9). مقاله مرورى انجامشده در ايران نيز نشان مىدهد كه بيش از •^مدرصد زنان سالمند ازنظر فعاليتهاى

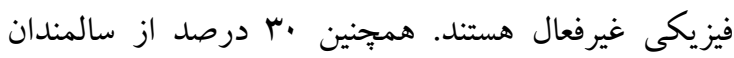

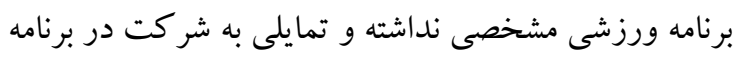
ورزشى ندارند(·) بـ بعلاوه غلام نيا و همكاران در مطالعه خود دريافتند كه كم تحر كى و بى تحر كى در زنان (همسران

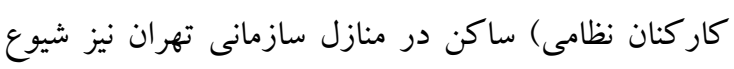

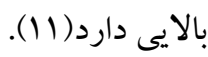


د مر مطالعه حاضر جهت تعيين حجم نمونه از فرمول C C $\left(\frac{z_{\alpha}+z_{\beta}}{C(r)}\right)^{2}+3$

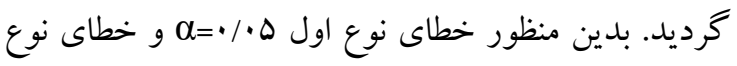
دوم r/r مشابه در داخل كشور(1) از ضريب همبستخى بين نخرش و كنترل رفتار درك ك rr=/r حجم نمونه با توجه به اطلاعات

$$
\text { فوق برابر با بها نفر بهدست آمد. }
$$

از روش نمونه گيرى تصادفى طبقهاى متناسب با حجم، 199

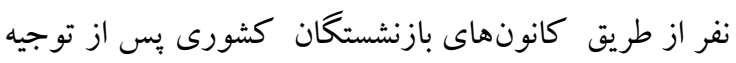

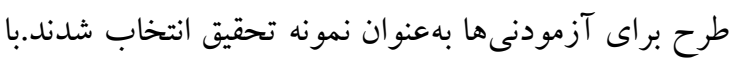
توجه به نسبت هر يكك از كانونها به حجم نمونه كل، تعداد

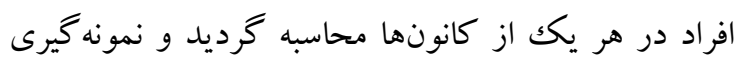

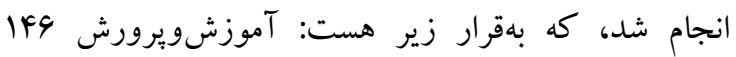
نفر (D/DVF

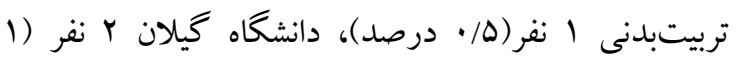

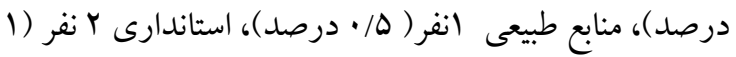

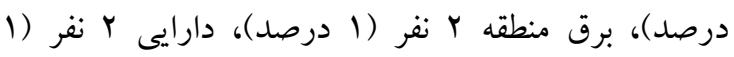

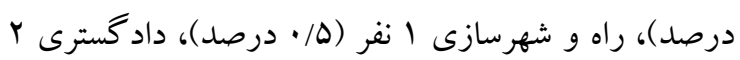
نفر (ادرصد).

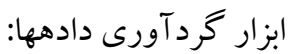
بهمنظور جمع آورى اطلاعات، از برسشنامه اطلاعات دمو گر افيك، برسشنامه استاندارد فعاليت فيزيكى سالمندان Physical (Activity Scale for the Elderly ) PASE

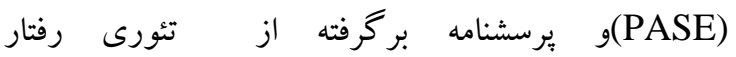

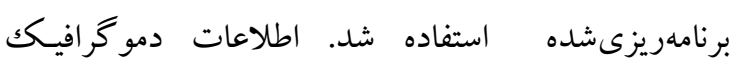
شـامل(سن، سن بازنشستخى، ميزان تحصيلات، وضعيت تأهل بانوان بازنشسته، وضعيت تحصيلات، نوع كانون بازنشستخى، مدتزمان بازنشستخى، شاخص توده بدنى )

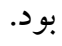
يرسشنامه استاندارد فعاليت فيزيكى سالمندانPASE شامل اطلاعاتى در خصوص زمان مصرفشده توسط فرد براى
مرتبط بـا انتخـاب فعاليـت فيزيكى بكـار خرفتهشـه اسـت، قــدرت بيش بينـى ايسن نظريـه در بسـيارى از مطالعـات در حوزهى تغيير رفتار به اثبات رسيده است؛ و بهعنوان يكى از

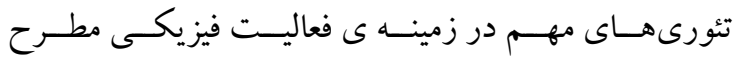

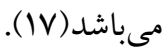
ازآنجاكه كمتر مطالعه اى در مورد زنان بر اساس تئورى رفتار برنامهريزىشده انجامشده است و اين قشر از جامعه نقش كليدى در مديريت سلامت خانوادهدارند لذا توجه

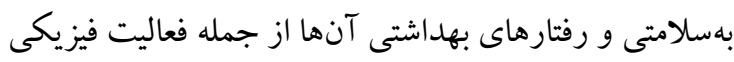

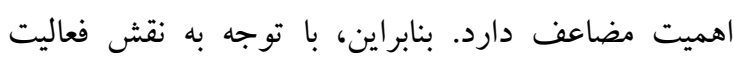

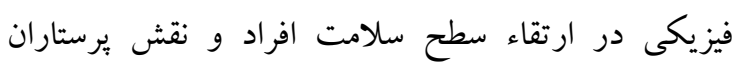
سلامت جامعه در ارتقاء سطح سلامت سالمندان و مناسب بودن تئورى رفتار برنامهريزىشده براى بررسى عوامل

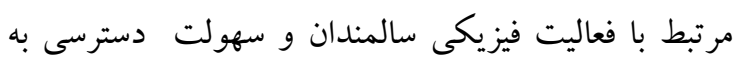

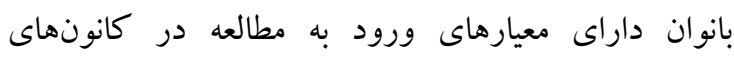

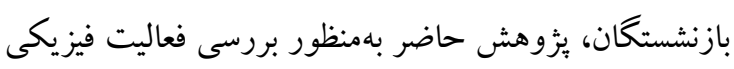

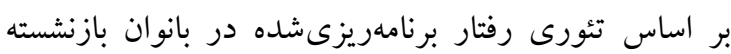
كانون بازنشستخان شهر رشت انجام شد.

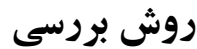 نوع مطالعه و نمونه گيرى:} يُزوهش حاضر يك مطالعه تحليلى - مقطعى است. جامعه

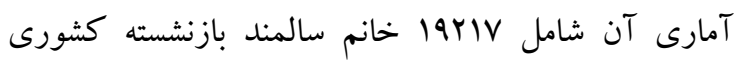

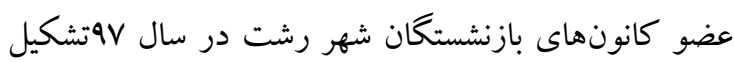
شده بود. بانوان بازنشسته شامل افرادى بودند سن •9 سال و

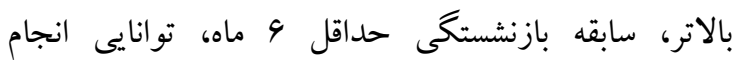

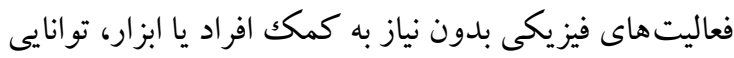

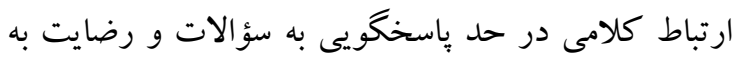
شر كت در مطالعه بودند. حجم نمونه 


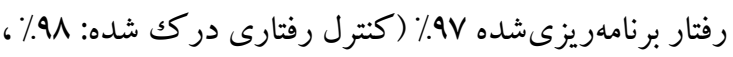
قصد رفتارى: 99\% ، نكرش: 99\%، هنجارهاى ذهنى: 91\%) و MM\% CVR ( كنترل رفتار درك شده: 94\% ، قصد رفتارى:

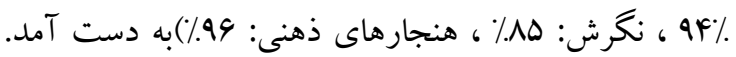
بهمنظور تعيين اعتبار صورى و ويايايى برسشنامها از ضريب آلفا كرونباخ ازنظر تجانس درونى استفاده گرديد. بدين منظور طى مطالعه پايلوت يُرسشنامه در اختيار يك گروه بيستنفرى از جمعيت هدف قرار گرفت. ضريب آلفا

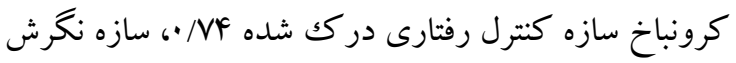
/VA •، هنجارهاى ذهنى /VA/ و سازه قصد رفتارى ضريب آلفا كرونباخ بr/· · به دست آمد. جهت تجزيهوتحليل، دادههاى جمع آورىشده از نرمافزار

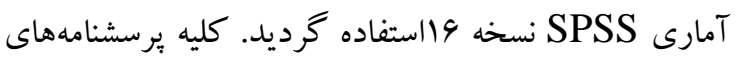
ذكرشده بهصورت مصاحبه توسط محقق تكميل شدند. براى محاسبه توده بدنى قد و وزن از ابزارها و شرايط استاندارد و

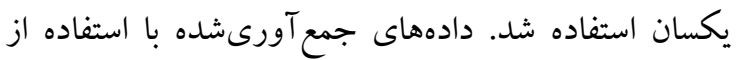

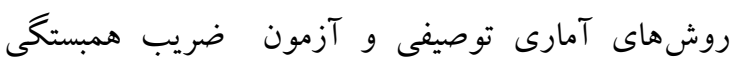
بيرسون تجزيه تحليل شدند.

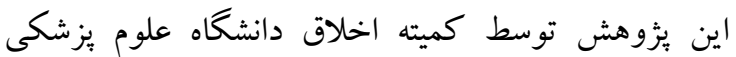

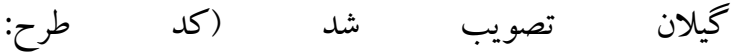
(IR.GUMS.REC.1396.316. همه شر كت كنند كان از اهداف يُزوهش و محرمانهبودن اطلاعات آكاه شدند و به آنها اطمينان داده شد كه اطلاعات آنها تنها جهت اهداف

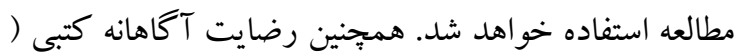
يا شفاهى) از همه شركت كنند كان قبل از تكميل برسش نامهها دريافت كرديد.

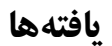

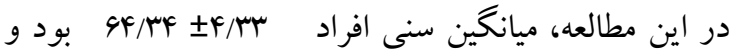
اكثريت نمونه هاى مورد يُزوهش در گروه سنى

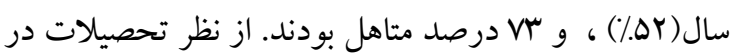

انجام ييادهروى و فعاليت فيزيكى متوسط و شديد و فعاليت خانكى و محيط كار در طى V روز گذشته است كه خود شامل سه قسمت فعاليت در اوقات فراغت( 9 سوال)، فعاليتهاى خانكى ( 4 سوال) و فعاليتهاى مرتبط با محيط كار (ا سوال) ست(19). امتياز كل PASE از طريق ضرب كردن مقدار زمانى كه در هر فعاليت مى گذرانند(ساعت/روز در طى ل روز گذشته) يا در فعاليت شر كت مى كنند(بلى /خير) با وزن PASE كه بهطور تجربى از طريق يكك نمونه جمعيت سالمندى انجامشده است، محاسبه مىشود و درنهايت تمام امتيازات PASE در سه بخش جمع مىشوند. واشبورن و همكاران گزارش كردند كه امتياز PASE در سالمندان ممكن است بين صفر تا . F.

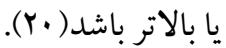
بِرسشنامه تئورى رفتار برنامهريزىشده بر اساس توصيههاى ايزن Aرzen تئورى رفتار برنامه ريزى شده، بِيه ريزى و ساخته شده است (YI) اين برسشنامه توسط حسينى براى دانشجويان دختر تنظيم وروايى و پايايى شده بود (1) و تا حدود زيادى با اين مطالعه متناسب بود؛ باين حال طى روايى و بايايى بعضى از گويه ها با نظر اساتيد

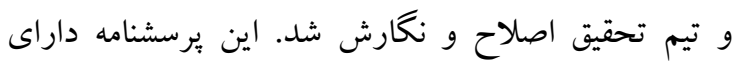
جهار سازه، نكرش شامل 11 سؤال، كنترل رفتارى درك شده شامل ·ل سؤال، قصد رفتارى شامل با سؤال و هنجارهاى ذهنى كه شامل 4 سؤال بود، سؤالات ينج كزينهاى بر مبناى ليكرت از كاملاً مخالفم انمره تا كاملاً موافقم ه نمره طراحى شد. بعد از طراحى بانكك سؤالات، يرسشنامه تئورى رفتار برنامهريزى شده جهت روايى متون در اختيار لا نفر ازصاحب نظران بِرستارى بهداشت قرار گرفت CVI و Cاخص روايى محتوى) ابزار فوق در سازههاى 


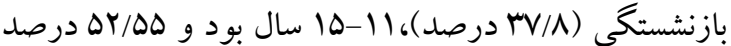

شركت كنند گان داراى شاخص توده بدنى،

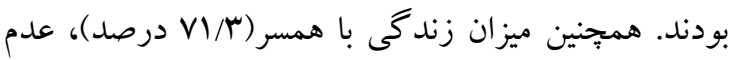

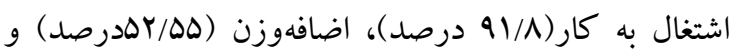
عضويت در كانون آموزشويرورش (VF/D درصد) مىباشد.
9V/V بازنشستكى ه بازنشستخى سM /هI/91/ Yاو ميانگين شاخص توده بدنى rV/·V I.I/VA زنان (1/

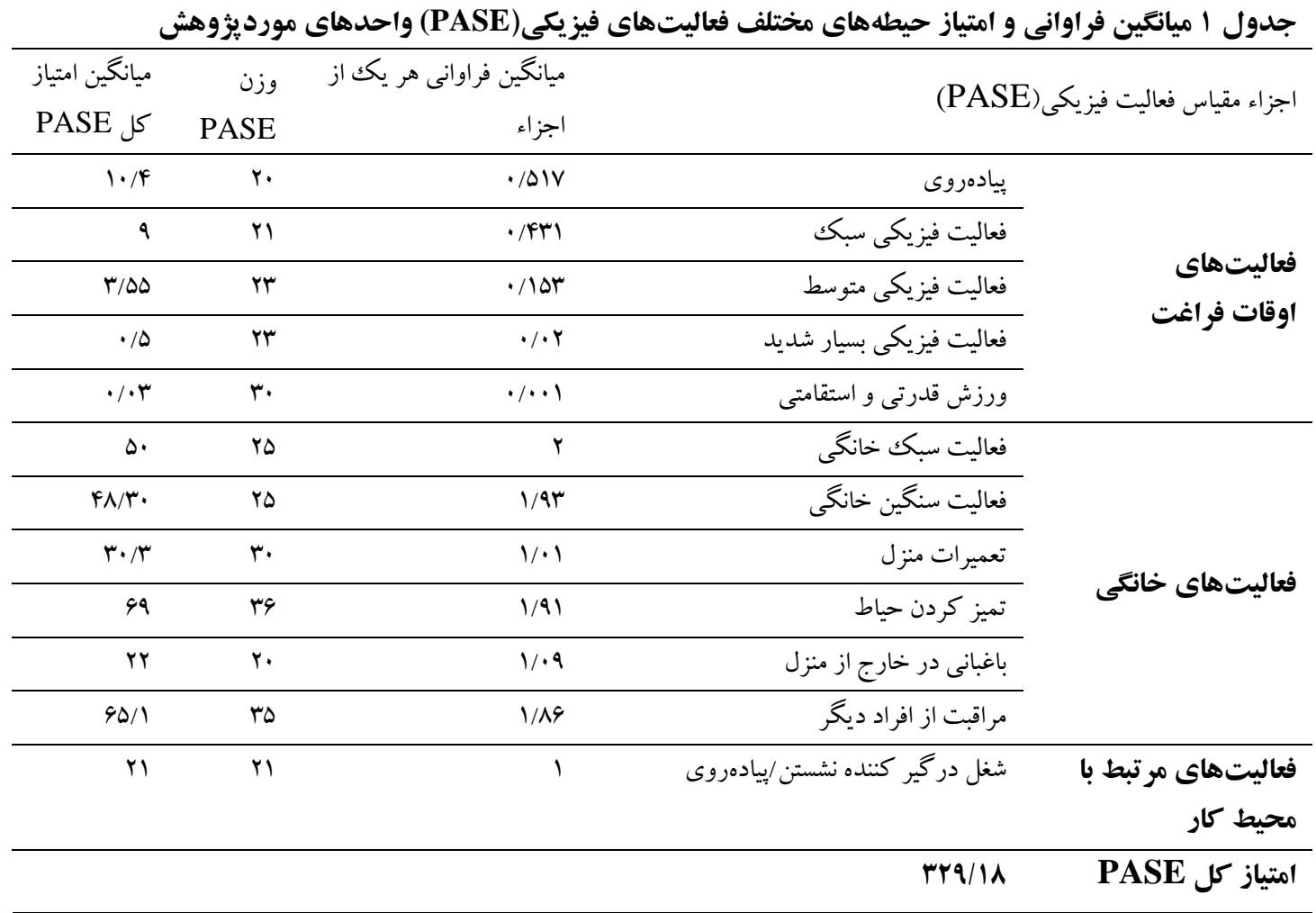

نمرهץ •/ • در اين حيطه را به خود اختصـاص داده بودنـد. در حيطه فعاليتهاى خانكلى بيشـترين امتيـاز (99 امتيـاز) در تميز كردن حياط و كمترين امتياز (Y امتياز) در ارتباط با باغبانى

$$
\text { در خارج از منزل بود. }
$$

جــدول اميـانخين فراوانـى و امتيـاز حيطـههاى مختلــف

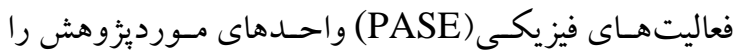
نشان مى دهد. اكثريت نمونسه هـاى مـورد مطالعهه در حيطه فعاليت هاى اوقات فراغات ، بياده روى داراى ميانگين نمـره 4 • ا و ورزشهاى قدرتى و استقامتى داراى كمترين ميانخين 
جدول r. شاخصهاى آمارى (ميانكين، انحراف معيار، حداقل و حداكثر) در سازههاى نظريه رفتار برنامهريزىشده

نمره سازههاى نظريه رفتار

\begin{tabular}{|c|c|c|c|c|}
\hline حد بالا & حد يايين & انحر اف معيار & ميانگين & 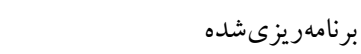 \\
\hline$\Delta \cdot$ & r. & $\Delta /{ }^{\prime} \Lambda$ & $4 \cdot 194$ & نمره كل كنترل رفتارى درك شده \\
\hline 4. & $M$ & $1 \cdot / r F$ & $4 \cdot / 10$ & نمره كل قصد رفتارى \\
\hline q. & $\Delta 9$ & $V / F \wedge$ & $\Lambda r / v i$ & نمره كل نكرش \\
\hline$r$. & 4 & f/ar & $r \Delta / r r$ & نمره كل هنجارهاى ذهنى \\
\hline
\end{tabular}

مورديزوهش در جدول شماره ب مشهود است. يافته ها نشـان

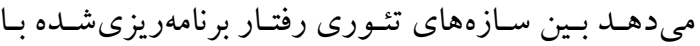
PASE رابطه معنى دار وجود ندارد ولى بين سازهها ازجمله سازه قصد رفتارى با كنترل رفتـارى درك شـده، نخـرش بـا كنتـرل رفتـارى دركك شـده و قصـد رفتـارى، و هنجارهـاى ذهنى با نكرش همبستگى وجود دارد ( ( P> (P).
جـدول Y شـاخصهاى آمـارى (ميـانگين، انحـر اف معيـار، حداقل و حداكثر) در سازههاى نظريه رفتار برنامهريزىشـده را نشان مى دهد. نمره كل نكرش اكثريست واحسدهاى مـورد

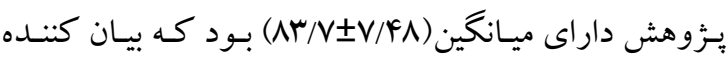
نكرش بالاى نمونه هاست. ماتريس همبستخى سـازههاى تئسورى رفتـار برنامهريزى شــده فعاليـت فيزيكـى بــا ميـز ان فعاليـت فيزيكـى در واحسـدهاى

جدول شماره ماتريس همبستكى سازههاى تئورى رفتار برنامهريزىشده فعاليت فيزيكى با ميزان فعاليت فيزيكى

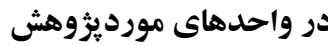

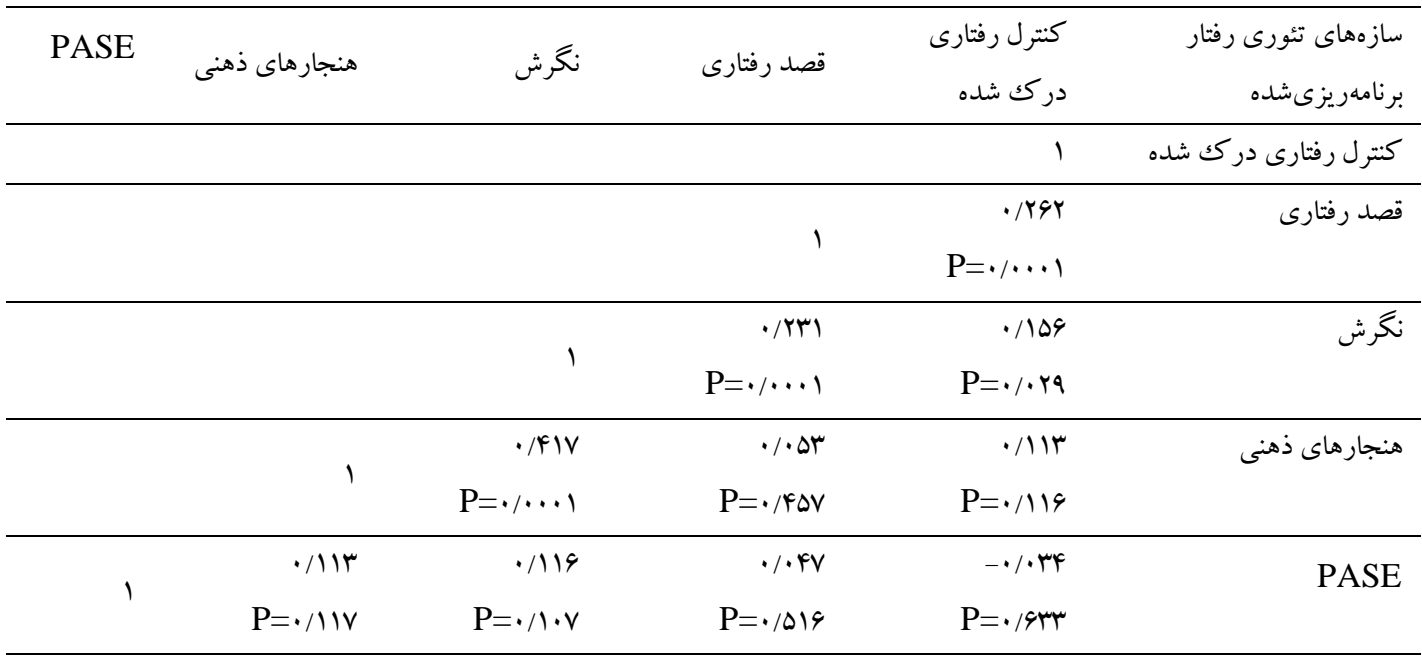

رشت انجام كرديد. اين تئورى شامل سازههاى قصد رفتارى، نخرش، هنجارهاى ذهنى و كنترل رفتارى درك لن شده مىباشد؛ كه توسط آيزن و فيش بن مطرح شد و بهطور
مطالعه حاضر بر اساس تئورى رفتار برنامهريزىشده و مبتنى برسازهاى اين تئورى بهمنظور ارتقاء فعاليت فيزيكى منظم بر روى بانوان بازنشسته عضو كانونهاى بازنشستگان شهر 
11\% كنترل رفتارى درك شده مثبت واحدهاى يثوهش مىباشد. كه با نتايج مطالعه غلام نيا و همكارانش(IM IM) با عنوان بهبود و تداوم رفتار ورزشى و شاخصهاى تنسنجى در زنان كاربردى از نظريه رفتار برنامهريزىشده در تهران (1) اثربخشى تئورى رفتار برنامهريزىشده براى بحث دربارهى آموزش استقامت بدن در بزرگسالان سالمند در كانادا (YM) همخوانى دارد، اما بامطالعه سورجى و همكارانش (هوسا) با عنوان اثربخشى تئورى رفتار برنامهريزىشده بر روى دانش آموزان دختر با اضافهوزن در بيرجند(YF) و مطالعه طباطبايى و همكارانش(IrNV) با عنوان تأثير مداخله آموزش مبتنى بر تئورى رفتار برنامهريزىشده بر فعاليت

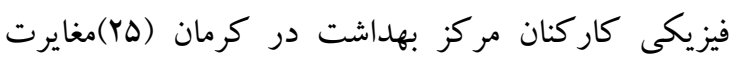
دارد، به نظر مىرسد دليل مغايرت يافتها با مطالعات سورجى و طباطبائى تفاوت سنى نمونه ها باشد، جونكه فعاليت فيزيكى يكك رفتار مبتنى بر نمونه و جامعه يزوهش

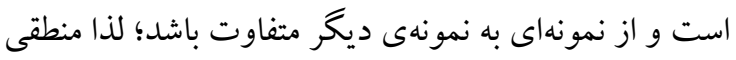
است يافتهها در مطالعهاى كه نمونها را بانوان بازنشسته جامعه گيلان تشكيل مىدهد با يافته هاى مطالعهى ديخر كه نمونه آن را دانش آموزان بيرجند تشكيل مىدهد متفاوت

همجنين در يُزوهش حاضر ميانگين نمره قصد رفتارى

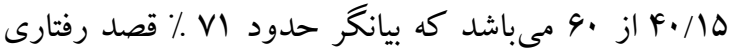
مثبت واحدهاى مورديزوهش بود. اين يافته با نتايج مطالعه غلام نيا و همكارانش(1)؛؛ از طرفى مطالعه شريفىنيا و همكارانش (هوبا) با عنوان تعيين تأثير مداخله مبتنى بر تئورى رفتار برنامهريزى بر فعاليت جسمانى زنان كارمند در تهران (Y9)مطابقت دارد، اما بامطالعه سورجى و همكاران (YF) همسو نمىباشد، به نظر مىرسد، دليل عدم تطابق در نمونهى جامعه ازنظر ويزگى ها و سن باشد زيرا مطالعه سورجى و همكاران در دانش آموزان انجام شد.
كسترده در مطالعات مختلف جهت تعيين نگرش و باورهاى مر تبط با انتخاب فعاليت فيزيكى بكارمى رود. ميانخين نمرهى فعاليت فيزيكى واحدهاى موردمطالعه، درصد نمره ابزار PASE بود كه در مقايسه بامطالعه فرمانبر و همكارانش(|q|| ) كه باهدف تعيين ميزان فعاليت جسمانى سالمندان بر اساس مدل ترانس تئورتيكال در رشت انجام شد(f أI امتياز PASE بالاتر به دست آمد. ازنظر يثوهشخر اين تفاوت مىتواند به اين دليل باشد كه مطالعه حاضر در خانمها انجام شد كه به نظر مىرسد خحانمها در سن يايينترى بازنشسته مىشوند. بعلاوه متوسط سن نمونههاى موردمطالعه نسبت به مطالعات مشابه يايين تر بود، همجنين مطالعه دكتر فرمانبر و همكاران در دو جنس زن و مرد انجام شد كه به نظر مىرسد خانمها بيروى بهترى از توصيه هاى بهداشتى ازجمله فعاليت فيزيكى دارند. همجينين در مطالعه حاضر در حيطهى فعاليت در اوقات فراغت، بيشترين ميانخين امتياز PASE را فعاليت بيادهروى(\&/• (1) و كمترين ميانگين امتياز PASE را ورزش قدرتى و استقامتى(س•/•)به خود اختصاص داده است. در حيطهى فعاليت خانكى، بيشترين ميانگين امتياز PASE را تميز كردن حياط و كمترين ميانگين امتياز PASE را فعاليت باغبانى خارج از منزل تشكيل مىداد. بيشترين ميانگين امتياز كل PASE را تميز كردن حياط(99) و كمترين امتياز را ورزش قدرتى و استقامتى(س+•)به خود اختصاص مىداد.

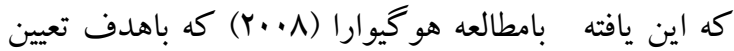
روايى و پايايى مقياس PASE در سالمندان (YY)انجام شده بود ، متفاوت است، در آن مطالعه امتياز PASE پايينتر ارزيابى شد كه عمدتاً به دليل تفاوت نمره محاسبهشده در حيطهى فعاليتهاى اوقات فراغت بود، بطوريكه در مطالعه هو گيوارا در فعاليتهاى اوقات فراغت كمترين امتياز PASE علاوه بر اين در مطالعه حاضر كسب ميانكين نمره

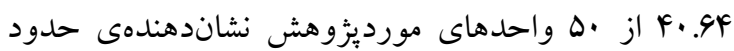


نداشت. به نظر مىرسد علت اختلاف نتايج مطالعه فوق با

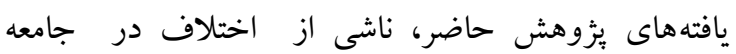
يُزوهش باشد و زنان كارمند وقت و شرايط متفاوتى نسبت به

$$
\text { بازنشستگان دارند. }
$$

سازههاى تئورى رفتار برنامهريزىشده(كنترل رفتارى درك

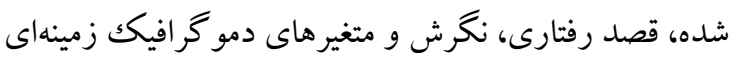

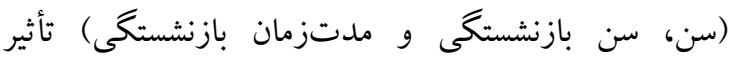

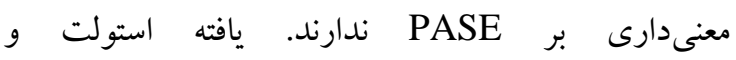

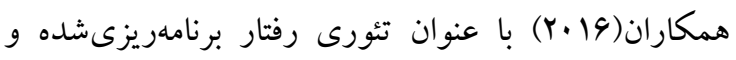
تغييرات فعاليت فيزيكى در سالمندان مسن هلند(Y)، (Y)،شان داد مداخله آموزشى بر روى فعاليت فيزيكى تأثير كذاشته

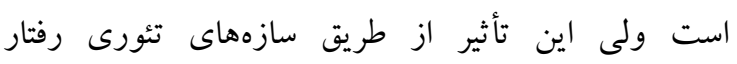
برنامهريزى شده نبوده است كه با يافته حاضر همسو مى باشد. ولى يافتها بامطالعه حسينى و همكارانش(rMM (IM ) با عنوان

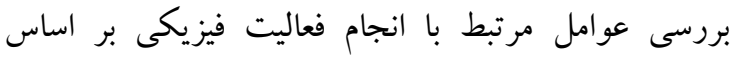
تئورى رفتار برنامهريزىشده در دانشجويان دختر تهران (Tr)و مطالعه موسوى و همكاران تحت عنوان تاثير مداخله مبتنى بر مدل TTM بر فعاليت فيزيكى برستاران شاغل در بخش مراقبت هاى ويزه مغايرت دارد(MY)، وى در تحقيق خوديافت نغرش به فعاليت فيزيكى ، كنترل رفتارى درك شده در مورد فعاليت فيزيكى با تمايل به فعاليت فيزيكى همبستخى مستقيم و مثبت دارد. هنجار ذهنى در مورد فعاليت فيزيكى ، كنترل رفتارى درك شده در مورد فعاليت فيزيكى و تمايل به انجام فعاليت فيزيكى با انجام فعاليت فيزيكى

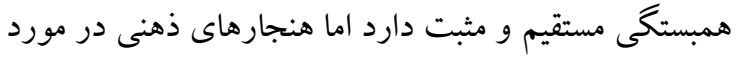
فعاليت فيزيكى با انجام فعاليت فيزيكى همبستخى ندئي ندارد.

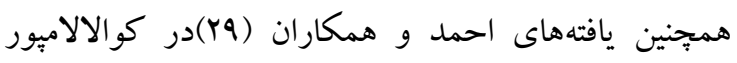

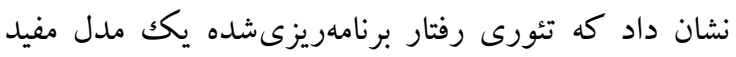

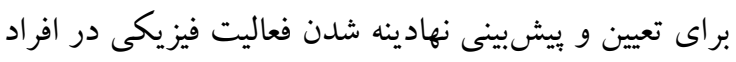

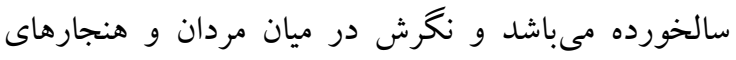

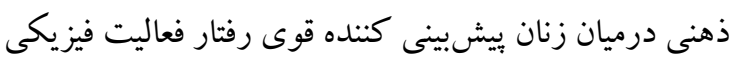

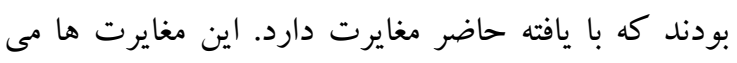

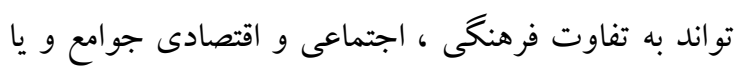

با توجه به حداكثر نمره ·9 براى نخرش در اين مطالعه

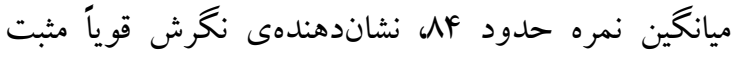

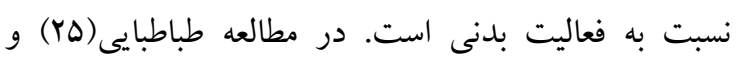
مطالعه صابر (|ج|) با عنوان بررسى سازههاى تئورى رفتار برنامهريزىشده در خصوص فعاليت بدنى دانشجويان

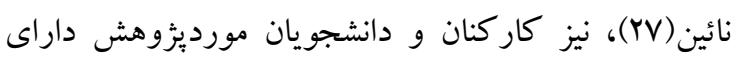

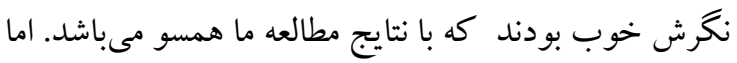

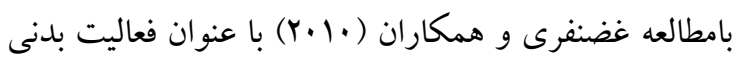
زنان ديابتى بر اساس تئورى رفتار برنامهريزىشده در تهران

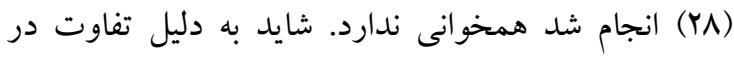
جامعه يُزوهش موردمطالعه باشد جونكه مطالعه فوق در زنان ديابتى در سن بارورى انجامشده بود.

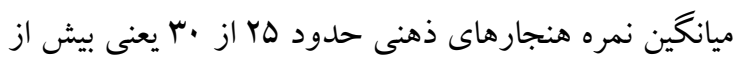

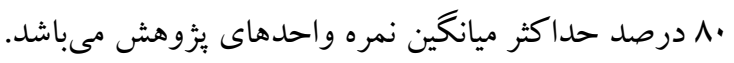
در بررسى تحليلى گزينههاى سازه هنجارهاى ذهنى ندره

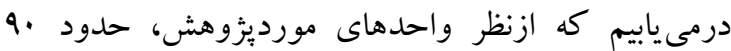
درصد از همسران، فرزندان، خواهر ان، برادران و افراد مهم

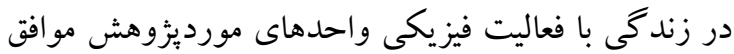

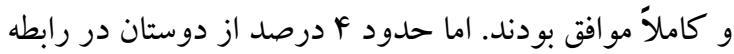

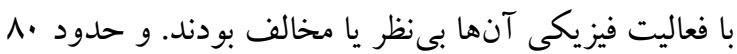
درصد واحدهاى مورديُزوهش آنجه ازنظر دوستان در رابطه لئه با فعاليت فيزيكى مهم بود را انجام مىدادند. همسو با اين مطالعه، در مطالعه احمد و همكاران(Y9)، خانواده و دوستان نقش بسيار مؤثرى را در تشويق بانوان سالمند به ورزش ايفا مى كردند. در مطالعه هيلو

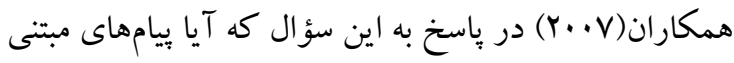
بر تئورى مى تواند در تركيب با فعاليتهاى شناختى، ميزان

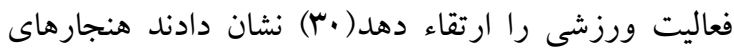

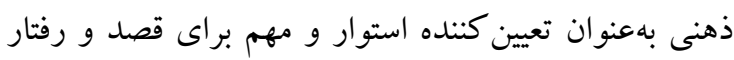

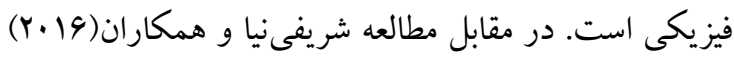

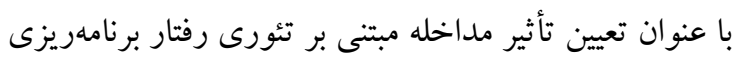

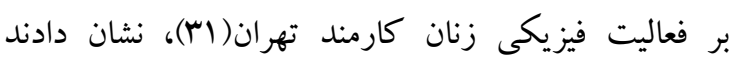

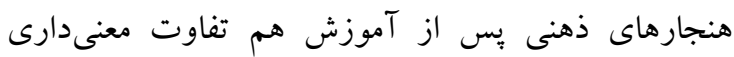




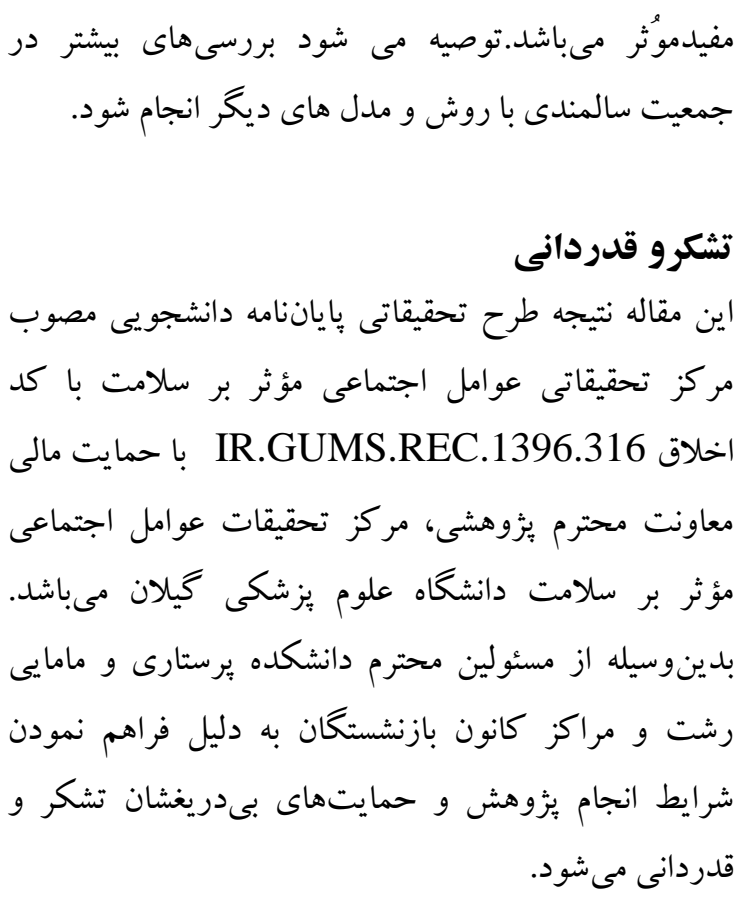

1.Organization WH. Global Strategy on Diet, Physical Activity and Health. Physical Activity and Women. 2016.

2.Organization WH. Global Strategy on Diet, Physical Activity and Health Physical activity 2010. Available from: Available from: http://www.who.int/dietphysicalactivity/pa/en/.

3.Afkar A AA, Rahmani M, Emami Sigaroudi A. Effect of exercise therapy on quality of life of patients with multiple sclerosis in Iran: a systematic review and meta-analysis Neurol Sci.. 2017: 38(11), pp. 1901-11.

4.Hallal PC, Andersen LB, Bull FC, Guthold R, Haskell W, Ekelund U, et al. Global physical activity levels: surveillance progress, pitfalls, and prospects. lancet. 2012;380(9838):247-57.

5.NM R. Role of Exercise in the Managment of Aging Effects. J Aging Physical Act. 2009:15(23):349-59(Persian).

6.Khajavi D, Farrokhi A, Jaberi MA, Kazemnejad A. The Effect of a Training Intervention Program on Fall-Related Motor Performance in the Male Elderly without Regular Physical Activity. Harakat. 2013;1(12):49-65.

7.Kallings L. Physical activity on prescription: Studies on physical activity level, adherence and cardiovascular risk factors. Institutionen för neurobiologi, vårdvetenskap och samhälle/Department of Neurobiology, Care Sciences and Society; thesis,2008-09-05

8.Trost SG SJ, Pate RR, Freedson PS, Taylor WC, Dowda M. Evaluating a Model of Parental Influence on Youth Physical Activity. Am J Prev Med. 2003:25(4):277-82.

9.Organization WH. Global Health Observatory (GHO): Prevalence of insufficient physical activity: Situation and trends [Internet]. 2008 [cited 2015 Jul 4].

10.Baker WL KS, Kenny AM. Effect of dehydropiandrosterone on muscle strength and physical function in older adults: a systematic review. Am Geriatr Soc. 2011:59(6):997-1002. 
11.Gholamnia Shirvani Z GF, Gharakhanlou R, Kazemnejad A. Improving and Maintaining Physical Activity and Anthropometric Indices in females from Tehran: Application of the Theory of Planned Behavior. Education and Community Health. 2016:2(4):13-24 (persian).

12.Parhoodeh Y KM, Bakhtiyari M, Delpisheh A. Effect of education based on Transtheoretical model on physical activity behavior in college students. Health System Research. 2012:8(2):320-9.

13.DiClemente RJ CR, Kegler MC. Emerging theories in health promotion practice and research: Strategies for improving public health. Jossey-Bass publisher. 2002.

14.Farmanbar R DL, Mirhadian L, Kazemnejad Leili E, Emami Sigarodi A. Physical activity on Transtheoretical model in older adulth Guilan. Applied environmental and biological sciences. 2014:;4(2):1-7.

15.Saffari M, Shojaeizadeh D, Ghofranipour F, Heydarnia A, Pakpour A H. Health Education \& Promotion Theories, Models \& Methods: Sobhan; . 2012:[Text in Persian].

16.Hackman C L, P. KA. Theory of reasoned action and theory of planned behavior-based dietary interventions in adolescents and young adults: a systematic review. Adolesc Health Med Ther. 2014;5:101-14.

17.Glanz K, Rimer B, Viswanath K. Health behavior and health education. 4 ed printed in the united state of American: Jossey-Bass. 2008.

18.Hosseini M, Khavari Z, Yaghmaie F, Alavi Majd H. Investigating the Factors Related to Exercise Based on Theory of Planned Behavior in Female Students at Shahid Beheshti University of Medical Sciences and Health Services.

2009;19(66):1-7(text in persian).

19.Farmanbar R, Dehghankar L, Mirhadian L, Kazemnejad Leili E, Emami Sigarodi A. Physical activity on Transtheoretical model in older adulth Guilan. Applied environmental and biological sciences. 2014;4(2):1-7[Text in Pertian].

20.Washburn RA, Smith KW, Jette AM, Janney CA. The Physical Activity Scale for the Elderly (PASE): Development and evaluation. . J Clin Epidemiol. 1993;46:153-62.

21.Ajzen I. Behavioral Intervention Based on the Theory of Planned Behavior 2011 [updated 2015].

22.Hagiwara A IN, Sawai K, Kazuma K. Validity and reliability of the Physical Activity Scale for the Elderly (PASE) in Japanese elderly people. Geriatr Gerontol Int.2008:8(3);14351.

23.Rachel N DJM, Farrell Mary Lou K elley M, Taylor J, Ryane Rhodes E. Testing the Efficacy of the Theory of Planned Behavior to Explain Strength Training in Older Adults. J Aging Phys Act.2007:15(1);1-12

24.Soorgi Z MM, Sharifzadeh G. The Impact of Planned Behavior Theory-Based Education on Female Students' Obesity-Related B,ehaviors. Modern Care J. 2015:12(4) ) Persian.

25.Ahmadi Tabatabaei SV TM, Nakheei N, Balali F. Effect of Educational Intervention Based on the Theory of Planned Behaviour on the Physical Activities of Kerman Health Center s Staff (2008). J Babol Univ Med Sci. 2010:12(2):62-9)

26.Shafieinia M HA, Kazemnejad A, Rajabi R. Effects of a Theory Based Intervention on Physical Activity Among Female Employees: A Quasi-Experimental Study. Asian J Sports Med. 2016:7(2)) Persian.

27.Saber F SH, Sharifrad GR. The survey of Theory of planned behavior constructs regarding girl student's physical activity in Naein payame NoorUniversity in 2012. J Health Syst Res 2013:9():1014-21. 
28.Gholamnia Shirvani Z, Ghofranipour F, Gharakhanlou R, Kazemnejad A. The effectiveness of a theory-based behavior change intervention to increase and maintain physical activity in female diabetic patients in Tehran, Iran. Payesh. 2016:5; 533-547

29.Ahmad MH SS, Mohd NI, Teng T, Abdul Mana Z, Mohd Sakian NI, et al. Applying theory of planned behavior to predict exercise maintenance in sarcopenic elderly. Clin Interv Aging. 2014:1551-61.

30.Hill C AC, Wright DB. Can theory-based messages in combination with cognitive prompts promote exercise in classroom settings? Soc Sci Med. 2007:65(5):1049-58.

31.Sharfieinia M HA, Kazemnejad A, Rajabi R. Effects of a Theory Based Intervention on Physical Activity Among Female Employees: A Quasi-Experimental Study. Asian J Sports Med. 2016:7(2);e31534.

32.Stolte E H-RM, Aartsen MJ, van Tilburg TG, Chorus A. The theory of planned behavior and physical activity change: outcomes of the Aging Well and Healthily Intervention Program for Older Adults. J Aging Phys Act. 2017 Jul;25(3):438-445.

33.Hosseini M KZ, Yaghmaie F, Alavi Majd H. Investigating the Factors Related to Exercise Based on Theory of Planned Behavior in Female Students at Shahid Beheshti University of Medical Sciences and Health Services.Advances in Nursing and Midwifery. 2009:19(66):1-7.. 34.Saghi Moosavi RF, Saghar Fatemi, Mohammad Ali Yazdanipour. The Effect of a TTMBased Intervention on Level of Physical Activity in ICU Nurses. Published online. 2017: December 5. 